\title{
Downregulation of protein disulfide-isomerase A3 expression inhibits cell proliferation and induces apoptosis through STAT3 signaling in hepatocellular carcinoma
}

\author{
RYOTA KONDO $^{1,2}$, KOUSUKE ISHINO ${ }^{1}$, RYUICHI WADA ${ }^{1}$, HIDEYUKI TAKATA ${ }^{2}$, \\ WEI-XIA PENG ${ }^{1}$, MITSUHIRO KUDO ${ }^{1}$, SHOKO KURE $^{1}$, YOHEI KANEYA ${ }^{1,2}$, \\ NOBUHIKO TANIAI $^{2}$, HIROSHI YOSHIDA ${ }^{2}$ and ZENYA NAITO ${ }^{1}$ \\ Departments of ${ }^{1}$ Integrated Diagnostic Pathology and \\ ${ }^{2}$ Gastrointestinal and Hepato-Biliary-Pancreatic Surgery, Nippon Medical School, Tokyo 113-8602, Japan
}

Received September 26, 2018; Accepted December 14, 2018

DOI: $10.3892 /$ ijo.2019.4710

\begin{abstract}
Protein disulfide-isomerase A3 (PDIA3) is a chaperone protein that modulates folding of newly synthesized glycoproteins and responds to endoplasmic reticulum (ER) stress. Previous studies reported that increased expression of PDIA3 in hepatocellular carcinoma (HCC) is a marker for poor prognosis. However, the mechanism remains poorly understood. The aim of the present study, therefore, was to understand the role of PDIA3 in HCC development. First, immunohistochemical staining of tissues from $53 \mathrm{HCC}$ cases revealed that HCC tissues with high PDIA3 expression exhibited a higher proliferation index and contained fewer apoptotic cells than those with low expression. In addition, the knockdown of PDIA3 significantly inhibited cell proliferation and induced apoptosis in HCC cell lines. These results suggest that PDIA3 regulates cell proliferation and apoptosis in HCC. An examination of whether PDIA3 knockdown induced apoptosis through ER stress revealed that PDIA3 knockdown did not increase ER stress marker, $78 \mathrm{kDa}$ glucose-regulated protein, in HCC cell lines. Furthermore, the association between PDIA3 and the signal transducer and activator of transcription 3 (STAT3) signaling pathway were investigated in vitro and in vivo. Immunofluorescence staining and co-immunoprecipitation experiments revealed colocalization and binding, respectively, of PDIA3 and STAT3 in HCC cell lines. The knockdown of PDIA3 decreased the levels of phosphorylated STAT3 (P-STAT3; Tyr705) and downstream proteins of the STAT3 signaling pathway: The anti-apoptotic
\end{abstract}

Correspondence to: Professor Zenya Naito, Department of Integrated Diagnostic Pathology, Nippon Medical School, 1-1-5 Sendagi, Tokyo 113-8602, Japan

E-mail: naito@nms.ac.jp

Key words: apoptosis, hepatocellular carcinoma, proliferation, protein disulfide-isomerase A3, signal transducer and activator of transcription 3 proteins (Bcl-2-like protein 1, induced myeloid leukemia cell differentiation protein Mcl-1, survivin and X-linked inhibitor of apoptosis protein). In addition, PDIA3 knockdown provided little inhibitory effect on cell proliferation in HCC cell lines treated with AG490, a tyrosine-protein kinase JAK/STAT3 signaling inhibitor. Finally, an association was demonstrated between PDIA3 and P-STAT3 expression following immunostaining of $35 \mathrm{HCC}$ samples. Together, the present data suggest that PDIA3 promotes HCC progression through the STAT3 signaling pathway.

\section{Introduction}

Hepatocellular carcinoma (HCC) is one of the most common causes of cancer-associated mortalities worldwide (1). The principal treatment for HCC is surgical resection or liver transplantation (2). However, in the period between 2001 and 2008, the cumulative recurrence rate following complete resection of the tumor remained high (40-60\% after 3 years) (3-5). Surgical treatment is often unavailable for patients with HCC who were diagnosed at an advanced stage. Multikinase inhibitors (sorafenib, regorafenib and lenvatinib) are approved for the systemic treatment of inoperable HCC. However, such drugs prolong the survival of patients with inoperable HCC for only a few months $(6,7)$. Therefore, it is necessary to investigate novel therapeutic targets for this disease.

The signal transducer and activator of transcription 3 (STAT3) pathway is one of the major signaling pathways that promote tumor progression in HCC (8). This pathway is stimulated by inflammatory cytokines and growth factors (9-11). Activation of STAT3 through phosphorylation of tyrosine 705 leads to the formation of dimers that subsequently move from the cytosol to the nucleus to bind DNA, and thereby regulate gene expression and promote cell proliferation and survival (9-11). In the case of the liver, the STAT3 signaling pathway is activated by chronic hepatitis (hepatitis B or C infections, alcoholic hepatitis and non-alcoholic steatohepatitis) (11). It has been demonstrated that activated STAT3 is associated with tumor invasiveness, metastasis and poor prognosis in HCC (12-14). 
Protein disulfide-isomerase A3 (PDIA3), also known as endoplasmic reticulum (ER) resident protein 57 or $58 \mathrm{kDa}$ glucose-regulated protein, is a thiol oxidoreductase with protein disulfide isomerase activity. PDIA3 modulates the folding of newly synthesized glycoproteins and misfolded proteins in the ER (15). This protein also protects cells from ER stress-induced apoptosis (15). Furthermore, it has a variety of functions in the cytosol and nucleus (15). In several types of cancer, PDIA3 forms a complex with STAT3 in the nucleus (16-18). A high frequency of PDIA3-STAT3 complex formation is a marker of poor prognosis and increases resistance to radiotherapy in laryngeal cancer through modulation of STAT3 activity (19). We have previously reported that the PDIA3 expression levels in HCC tissues are higher than those in adjacent non-cancerous tissues, and that they are associated with overall survival time (20). However, the biological role of PDIA3 in HCC remains unclear.

The aim of the present study was to understand the role of PDIA3 in HCC. PDIA3 expression levels, the effects of PDIA3 knockdown and the association between PDIA3 and STAT3 in HCC were examined. The expression of PDIA3 in HCC tissues was associated with cell proliferation, survival and expression of phosphorylated STAT3 (P-STAT3) in HCC. PDIA3 knockdown in HCC cell lines inhibited cell proliferation and induced apoptosis by suppression of the STAT3 signaling pathway. In the presence of the tyrosine-protein kinase JAK/STAT3 signaling inhibitor AG490, PDIA3 knockdown provided little additional inhibition of cell growth. These data suggest that PDIA3 promotes tumor development in patients with HCC through the STAT3 signaling pathway.

\section{Materials and methods}

Clinical samples. A total of 53 patients with HCC who underwent hepatectomy without preoperative therapy at the Nippon Medical School Hospital (Tokyo, Japan) between January 2016 and February 2018, were enrolled in this study. The tumor and adjacent normal tissues from these patients were fixed with $10 \%$ formalin at room temperature for $24 \mathrm{~h}$ within $2 \mathrm{~h}$ of resection and embedded in paraffin. Among them, $35 \mathrm{HCC}$ samples were formalin-fixed within $30 \mathrm{~min}$ of resection and were used for immunostaining of P-STAT3. The baseline characteristics of the patients are summarized in Table I. This study was conducted according to the Declaration of Helsinki and the Japanese Society of Pathology, and was given official approval by the Ethics Committee of the Nippon Medical School Hospital (approval no. 29-03-908). Written informed consent was obtained from all patients.

Cell culture. Human hepatoma cell lines (Huh-7 and HuH-1) were obtained from the Japanese Collection of Research Bioresources cell bank (Osaka, Japan). A normal human hepatocyte cell line (THLE-2) was obtained from the American Type Culture Collection (Manassas, VA, USA). Huh-7 and HuH-1 cells were cultured in RPMI-1640 medium (Gibco; Thermo Fisher Scientific, Inc., Waltham, MA, USA) supplemented with $10 \%$ heat-inactivated fetal bovine serum (FBS; Nichirei Biosciences, Inc., Tokyo, Japan) at $37^{\circ} \mathrm{C}$ in a humidified $5 \% \mathrm{CO}_{2}$ atmosphere.
The THLE-2 cell line was maintained in Bronchial Epithelial Cell Growth Medium (BEGM; Lonza Group Ltd., Basel, Switzerland) without gentamycin/amphotericin and epinephrine but with added $5 \mathrm{ng} / \mathrm{ml}$ epidermal growth factor (Corning, Inc., Corning, NY, USA), $70 \mathrm{ng} / \mathrm{ml}$ phosphoethanolamine (Sigma-Aldrich; Merck KGaA, Darmstadt, Germany) and $10 \%$ FBS. The THLE-2 cells were cultured in RPMI-1640 medium with $10 \%$ FBS for 7 days at $37^{\circ} \mathrm{C}$ in a humidified $5 \% \mathrm{CO}_{2}$ atmosphere prior to protein extraction. A JAK/STAT3 signaling inhibitor, AG490 (Merck KGaA), dissolved in dimethylsulfoxide (DMSO; Wako Pure Chemical Industries, Ltd., Osaka, Japan), was used for the suppression of STAT3 signaling at 25 or $100 \mu \mathrm{M}$ in cell growth or western blotting, respectively.

PDIA3 knockdown. Short-interfering RNAs (siRNAs) were purchased from Thermo Fisher Scientific, Inc. The two PDIA3 siRNAs used were designated PDIA3 si-1 and PDIA3 si-2 and knownas Silencer ${ }^{\circledR}$ Select Pre-designed siRNA cat.no.4392420, ID s6227 (5'-GGAAUAGUCCCAUUAGCAAtt-3') and ID s6229 (5'-GCAACUUGAGGGAUAACUAtt-3'), respectively. Silencer ${ }^{\circledR}$ negative control \#1 siRNA (cat. no. 4390844) was used as a negative control (Ctrl si). The transfection of the siRNA was performed using Lipofectamine ${ }^{\circledR}$ RNAiMAX Reagent (Invitrogen; Thermo Fisher Scientific, Inc.), according to the manufacturer's protocol. The optimal concentration of siRNA for use in transfections was $5 \mathrm{nM}$. The medium was refreshed $24 \mathrm{~h}$ after cell seeding and the cells were cultured for a further 48 and $72 \mathrm{~h}$ for the apoptosis and cell cycle assay and western blotting, respectively. The cell transfection efficiency was measured by reverse transcription-quantitative polymerase chain reaction (RT-qPCR) and western blotting, as described below.

$R T$ - $q$ PCR assay. A total of $2.5 \times 10^{5}$ cells were seeded in $60-\mathrm{mm}$ dishes and cultured for $48 \mathrm{~h}$. Total RNA was extracted using the NucleoSpin RNA kit (Takara Bio Inc., Otsu, Japan), and $1 \mu \mathrm{g}$ of total RNA was used for reverse transcription using the SuperScript VILO cDNA Synthesis kit (Thermo Fisher Scientific, Inc.) following the manufacturer's protocol. The reaction conditions were as follows: $25^{\circ} \mathrm{C}$ for $10 \mathrm{~min}, 42^{\circ} \mathrm{C}$ for $60 \mathrm{~min}$ and $85^{\circ} \mathrm{C}$ for $5 \mathrm{~min}$. The qPCR was performed for PDIA3 and 18S rRNA (as an internal standard) using the StepOnePlus Real-Time PCR system with TaqMan probes and primers (18S, cat. no. Hs 03928990_g1; PDIA3, cat. no. Hs 04194196_g1) (all Thermo Fisher Scientific, Inc.). The cycling conditions were as follows: $20 \mathrm{sec}$ at $95^{\circ} \mathrm{C}$, followed by 40 cycles of $1 \mathrm{sec}$ at $95^{\circ} \mathrm{C}$ and $20 \mathrm{sec}$ at $60^{\circ} \mathrm{C}$. The RT-qPCR results are expressed as the ratio of target mRNA to $18 \mathrm{~S}$ rRNA and calculated using the $2^{-\Delta \Delta \mathrm{Cq}}$ method (21). The gene expression levels were measured in triplicate.

Protein extraction and western blotting. Total protein was extracted using urea/thiourea buffer containing $7 \mathrm{M}$ urea (Wako Pure Chemical Industries, Ltd.), $2 \mathrm{M}$ thiourea (Nacalai Tesque, Inc., Kyoto, Japan), 3\% 3-(3-[cholamidopropyl]-di methylammonio)-1-propanesulfonate (Dojindo Molecular Technologies, Inc., Kumamoto, Japan) and 1\% Triton X-100 (Sigma-Aldrich; Merck KGaA) from the cells after $96 \mathrm{~h}$ of siRNA transfection, as described previously (22). The protein 
Table I. Associations between clinicopathological factors and PDIA3 or P-STAT3 levels in hepatocellular carcinoma.

\begin{tabular}{|c|c|c|c|c|c|c|c|c|}
\hline \multirow[b]{2}{*}{ Characteristics } & \multicolumn{4}{|c|}{ PDIA3 expression } & \multicolumn{4}{|c|}{ P-STAT3 status } \\
\hline & $\mathrm{n}$ & High $(n=29)$ & Low $(n=24)$ & P-value & $\mathrm{n}$ & Positive ( $n=15$ ) & Negative $(n=20)$ & P-value \\
\hline Sex & & & & 0.127 & & & & 0.372 \\
\hline Male & 44 & 22 & 22 & & 26 & 10 & 16 & \\
\hline Female & 9 & 7 & 2 & & 9 & 5 & 4 & \\
\hline Age, years & & & & 0.226 & & & & 0.599 \\
\hline$<65$ & 13 & 9 & 4 & & 11 & 4 & 7 & \\
\hline$\geq 65$ & 40 & 20 & 20 & & 24 & 11 & 13 & \\
\hline HBsAg & & & & 0.805 & & & & 0.605 \\
\hline Positive & 6 & 3 & 3 & & 6 & 2 & 4 & \\
\hline Negative & 47 & 26 & 21 & & 29 & 13 & 16 & \\
\hline HCV infection & & & & 0.707 & & & & 0.767 \\
\hline Positive & 25 & 13 & 12 & & 15 & 6 & 9 & \\
\hline Negative & 28 & 16 & 12 & & 20 & 9 & 11 & \\
\hline Cirrhosis & & & & 0.68 & & & & 0.599 \\
\hline Yes & 17 & 10 & 7 & & 11 & 4 & 7 & \\
\hline No & 36 & 19 & 17 & & 24 & 11 & 13 & \\
\hline $\mathrm{AFP}, \mathrm{ng} / \mathrm{ml}$ & & & & 0.315 & & & & 0.486 \\
\hline$<20$ & 36 & 18 & 18 & & 21 & 10 & 11 & \\
\hline$\geq 20$ & 17 & 11 & 6 & & 14 & 5 & 9 & \\
\hline $\mathrm{DCP}, \mathrm{mAU} / \mathrm{ml}$ & & & & 0.15 & & & & 0.762 \\
\hline$<40$ & 23 & 10 & 13 & & 13 & 6 & 7 & \\
\hline$\geq 40$ & 30 & 19 & 11 & & 22 & 9 & 13 & \\
\hline Tumor size ${ }^{\mathrm{a}}, \mathrm{cm}$ & & & & 0.99 & & & & 0.503 \\
\hline$<5$ & 42 & 23 & 19 & & 26 & 12 & 14 & \\
\hline$\geq 5$ & 11 & 6 & 5 & & 9 & 3 & 6 & \\
\hline Tumor number & & & & 0.19 & & & & 0.834 \\
\hline 1 & 51 & 27 & 24 & & 33 & 14 & 19 & \\
\hline$\geq 2$ & 2 & 2 & 0 & & 2 & 1 & 1 & \\
\hline Vascular invasion & & & & 0.442 & & & & 0.419 \\
\hline Positive & 17 & 8 & 9 & & 8 & 2 & 6 & \\
\hline Negative & 36 & 21 & 15 & & 27 & 13 & 14 & \\
\hline UICC stage $^{\mathrm{b}}$ & & & & 0.624 & & & & 0.245 \\
\hline I & 35 & 20 & 15 & & 26 & 13 & 13 & \\
\hline II & 18 & 9 & 9 & & 9 & 2 & 7 & \\
\hline III & 0 & 0 & 0 & & 0 & 0 & 0 & \\
\hline IV & 0 & 0 & 0 & & 0 & 0 & 0 & \\
\hline Differentiation & & & & 0.697 & & & & 0.827 \\
\hline Good & 19 & 10 & 9 & & 10 & 5 & 5 & \\
\hline Moderate & 30 & 16 & 14 & & 23 & 9 & 14 & \\
\hline Poor & 4 & 3 & 1 & & 2 & 1 & 1 & \\
\hline
\end{tabular}

${ }^{a}$ The largest diameter. ${ }^{b}$ Tumor-Node-Metastasis Classification of Malignant Tumors, 8 th Edition (44). AFP, $\alpha$-fetoprotein; DCP, des- $\gamma$-carboxy prothrombin; $\mathrm{HBsAg}$, hepatitis B surface antigen; $\mathrm{HCV}$, hepatitis $\mathrm{C}$ virus; PDIA3, protein disulfide-isomerase A3; P-STAT3, phosphorylated signal transducer and activator of transcription 3; UICC, Union for International Cancer Control.

concentration was determined using Pierce ${ }^{\circledR} 660 \mathrm{~nm}$ Protein Assay Reagent (Thermo Fisher Scientific, Inc.). A total of $10 \mu \mathrm{g}$ protein from each cell extract was loaded onto and separated by $5-20 \%$ SDS-PAGE (e-PAGEL ${ }^{\circledR}$; ATTO Corporation,
Tokyo, Japan) and then transferred to a polyvinylidene difluoride membrane in a Trans-Blot ${ }^{\circledR}$ Turbo $^{\text {TM }}$ Transfer Pack using a Trans-Blot Turbo transfer system (both Bio-Rad Laboratories, Inc., Hercules, CA, USA). The membranes were 
blocked for $1 \mathrm{~h}$ with $5 \%$ skimmed milk in TBS containing $0.2 \mathrm{M}$ Tris- $\mathrm{HCl}, 150 \mathrm{mM} \mathrm{NaCl}$ and $0.01 \%$ Tween-20, and then incubated with specific primary antibodies overnight at $4{ }^{\circ} \mathrm{C}$. The antibodies to the following proteins were used: PDIA3 (cat. no. ab13506; 1:2,000), induced myeloid leukemia cell differentiation protein Mcl-1 (cat. no. ab32087; 1:2,000), 78 kDa glucose-regulated protein (GRP78; cat no. ab21685; 1:2,000) (all Abcam, Cambridge, UK), STAT3 (cat. no. 9139; 1:2,000), P-STAT3 (Tyr705; cat. no. 9145; 1:2,000), survivin (cat. no. 2808; 1:2,000), X-linked inhibitor of apoptosis protein (XIAP; cat. no. 14334; 1:2,000), Bcl-2-like protein 1 (Bcl-XL; cat. no. 2764; 1:2,000), cyclin D1 (cat. no. 2978; 1:1,000) (all Cell Signaling Technology, Inc., Danvers, MA, USA), B-cell lymphoma 2 (Bcl-2; cat. no. sc-492; 1:500; Santa Cruz Biotechnology, Inc., Dallas, TX, USA), cellular tumor antigen p53 (cat. no. M7001; 1:1,000; Dako; Agilent Technologies, Inc., Santa Clara, CA, USA) and $\beta$-actin (cat. no. A5316; 1:10,000; Sigma-Aldrich; Merck KGaA). Following washing in TBS with $0.01 \%$ Triton $\mathrm{X}-100$ for $30 \mathrm{~min}$, the membranes were incubated with a horseradish peroxidase-conjugated secondary antibody (cat. no. A106PU; 1:10,000; American Qualex Scientific Products, San Clemente, CA, USA) for $1 \mathrm{~h}$ at room temperature. The immunoreactive products were visualized using SuperSignal West Dura Extended Duration Substrate for each protein, and SuperSignal West Pico Chemiluminescence substrate (both Thermo Fisher Scientific, Inc.) for $\beta$-actin. The data were quantified by Quantity One 1-D analysis software version 4.6.2 (Bio-Rad Laboratories, Inc.). The experiments were performed $\geq 3$ times.

Immunoprecipitation. The total protein was extracted from cells $96 \mathrm{~h}$ after seeding. The cells were lysed in Pierce ${ }^{\mathrm{TM}}$ IP Lysis Buffer (Thermo Fisher Scientific, Inc.) and protease inhibitor (P8340; Sigma-Aldrich; Merck KGaA) for $10 \mathrm{~min}$ on ice after washing in PBS. The cell lysates were centrifuged at $20,000 \mathrm{x} \mathrm{g}$ for $10 \mathrm{~min}$ at $4^{\circ} \mathrm{C}$. The resulting supernatant was collected as a cell extract. Cell lysate $(2 \mathrm{mg})$, antibody $(3 \mu \mathrm{g})$, and protein A/G PLUS-Agarose $(30 \mu \mathrm{l})$ were combined and incubated overnight at $4^{\circ} \mathrm{C}$. The mixture was purified using Sigma Prep Spin Columns with Break-Away Tips (Sigma-Aldrich; Merck KGaA) and the proteins collected were used for immunoblotting with antibodies against PDIA3 and STAT3. Normal mouse IgG (3 $\mu$ g; cat. no. SC-2025; Santa Cruz Biotechnology, Inc.) was used as a negative control for the immunoprecipitation experiments.

Cell proliferation assay. Cells were seeded in 96-well plates, at a density of 5,000 cells per well, and cultured at $37^{\circ} \mathrm{C}$ in a humidified $5 \% \mathrm{CO}_{2}$ atmosphere following siRNA transfection with PDIA3 si-1, PDIA3 si-2 or Ctrl si, as described above. After $0,24,48,72$ and $96 \mathrm{~h}$ of proliferation, cells were incubated with the WST- 8 cell-counting reagent (Dojindo Molecular Technologies, Inc.) for $2 \mathrm{~h}$ at $37^{\circ} \mathrm{C}$. The optical density of the culture solution in each well was determined at $450 \mathrm{~nm}$ using a microplate absorbance reader (iMark ${ }^{\mathrm{TM}}$; Bio-Rad Laboratories, Inc.). The experiments were performed $\geq 3$ times.

Apoptosis analysis. Cells $\left(5 \times 10^{5}\right)$ were seeded in a $75-\mathrm{ml}$ flask and cultured in $10 \mathrm{ml}$ RPMI-1640 medium. The medium was changed $24 \mathrm{~h}$ after PDIA3 siRNA treatment. Floating and attached cells were collected $72 \mathrm{~h}$ after seeding. Double staining with Annexin $\mathrm{V}$ and ethidium homodimer III was performed using the Apoptotic, Necrotic, and Healthy Cells Quantification kit (Biotium, Inc., Freemont, CA, USA), following the manufacturer's protocol. The apoptotic cells were counted by flow cytometry on a BD FACSCanto ${ }^{\mathrm{TM}}$ II flow cytometer and analyzed using BD FACSDiva ${ }^{\mathrm{TM}}$ software version 6.1.3 (both Becton, Dickinson and Company, Franklin Lakes, NJ, USA). The experiments were performed $\geq 3$ times.

Cell cycle analysis. Cell harvesting was performed in the same manner as for the apoptosis analysis. The collected cells were washed in PBS and fixed in $100 \%$ methanol for $10 \mathrm{~min}$. The cells were incubated with RNase $(0.25 \mathrm{mg} / \mathrm{ml})$ for $30 \mathrm{~min}$ at $37^{\circ} \mathrm{C}$. Propidium iodide $(50 \mu \mathrm{g} / \mathrm{ml})$ was then added and incubated for $30 \mathrm{~min}$ at $4^{\circ} \mathrm{C}$ in the dark. The stained cells were analyzed by flow cytometry on a BD FACSCanto II flow cytometer and analyzed using BD FACSDiva software version 6.1.3. The experiments were performed $\geq 3$ times.

Hematoxylin and eosin staining. Tissue sections (4 $\mu \mathrm{m}$ thickness) were used for hematoxylin eosin staining. Following deparaffinization, the sections were stained hematoxylin (Merck $\mathrm{KGaA}$ ) for $30 \mathrm{~min}$ at room temperature, and eosin (Wako Pure Chemical Industries, Ltd.) for $20 \mathrm{~min}$ at room temperature, following washing in water. The sections were then washed and dehydrated. These sections were evaluated manually under a light microscope (x100 magnification; Olympus Corporation, Tokyo, Japan).

Immunostaining and scoring. Tissue sections ( $4 \mu \mathrm{m}$ thickness) were used for immunostaining. Following deparaffinization, sections were pretreated at $121^{\circ} \mathrm{C}$ for $15 \mathrm{~min}$ in $10 \mathrm{mM}$ citrate buffer ( $\mathrm{pH}$ 6.0) for PDIA3 and proliferation marker protein Ki-67 staining, and Histofine ${ }^{\circledR}$ Antigen Activation Liquid (pH 9.0; Nichirei Biosciences, Inc.) for P-STAT3 staining. Endogenous peroxidase was blocked in $100 \%$ methanol (Wako Pure Chemical Industries, Ltd.) containing 0.3\% hydrogen peroxide (Wako Pure Chemical Industries, Ltd.) for $30 \mathrm{~min}$ at room temperature. The sections were then incubated with antibodies for PDIA3 (1:500), P-STAT3 (1:400) and Ki-67 (MIB-1; cat. no. M7240; 1:100; Dako; Agilent Technologies, Inc.) in PBS containing $1 \%$ bovine serum albumin (Sigma-Aldrich; Merck KGaA) for $16 \mathrm{~h}$ at $4^{\circ} \mathrm{C}$. The sections were further incubated with Histofine Simple Stain ${ }^{\mathrm{TM}}$ MAX PO (rabbit or mouse; Nichirei Biosciences, Inc.) for $30 \mathrm{~min}$ at room temperature, and peroxidase activity was visualized by 3,3' diaminobenzidine. The sections were then counterstained with hematoxylin at room temperature for $1 \mathrm{~min}$.

For PDIA3, the intensity and proportion of stained tumor cells were semi-quantitated. If the tumor cell staining was not apparent, the intensity and proportion were scored as 0 . If it was apparent, the intensity of tumor cell staining was categorized into three grades: 1 , weak; 2 , moderate; and 3, strong. The proportional score of stained cells was also divided into three grades: $1,<10 \% ; 2,10-50 \%$; and $3,>50 \%$. A total score was calculated as the sum of the intensity and proportional scores. Two investigators evaluated the scores in a blind manner and the mean score 

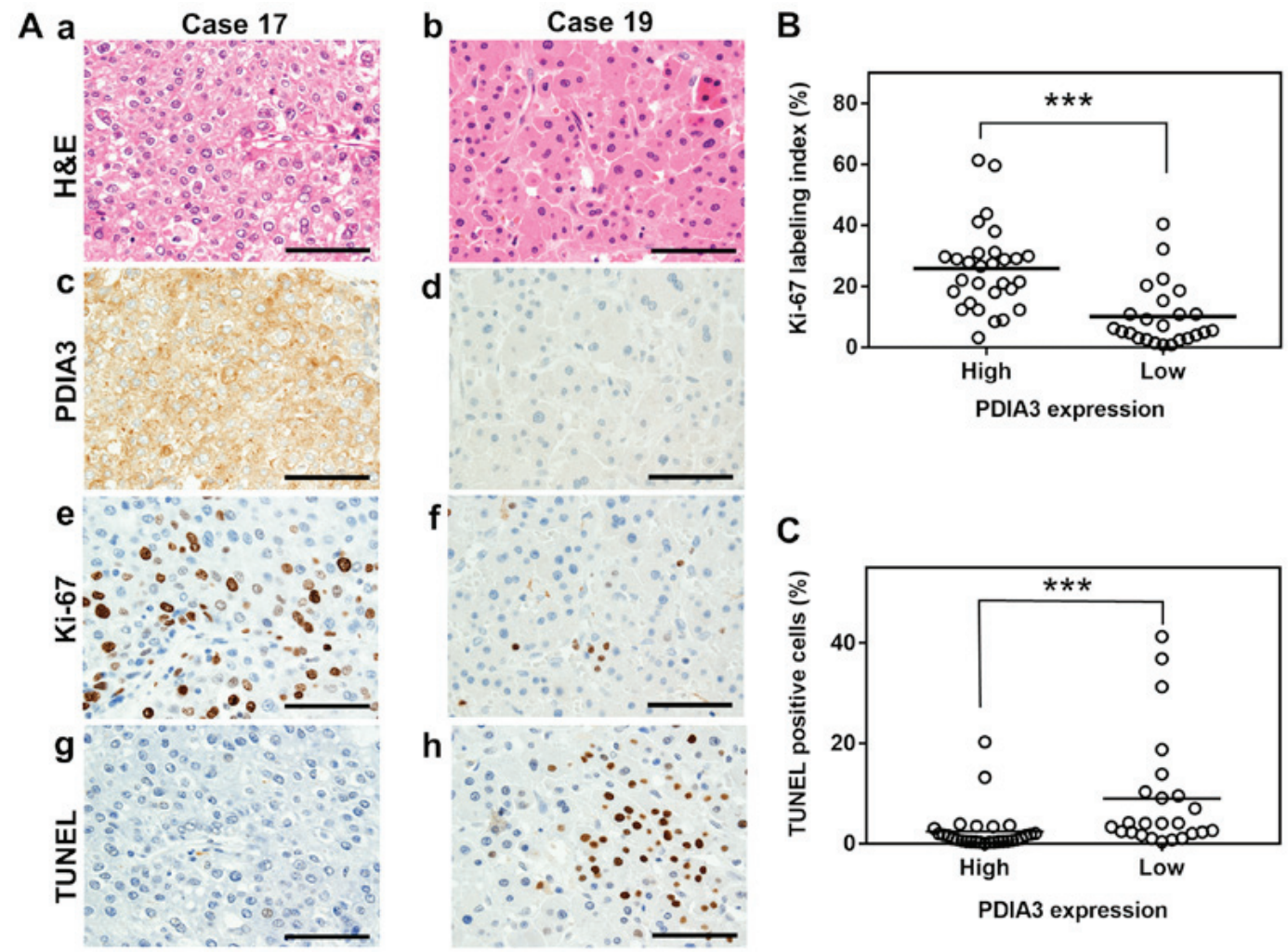

Figure 1. Association between PDIA3 expression and cell proliferation and apoptosis in HCC tissues. (A) Representative histological and immunohistochemistry staining of two HCC tissues (x600 magnification). The tissues were examined by (a and b) H\&E staining, immunohistochemistry staining with antibodies against (c and d) PDIA3 and (e and f) Ki-67, and ( $g$ and $h$ ) the TUNEL assay. The HCC tissue of case 17 exhibits high expression of PDIA3 and that of case 19 shows low expression. Scale bar, $50 \mu \mathrm{m}$. Scatter plots of (B) Ki-67 index values and (C) the percentage of TUNEL positive cells in HCC tissues with high (score, $4 \leq$ ) and low (score, 4>) PDIA3 expression. ${ }^{* * *} \mathrm{P}<0.001$ (Mann-Whitney U-test). PDIA3, protein disulfide-isomerase A3; Ki-67, proliferation marker protein Ki-67; TUNEL, terminal deoxynucleotidyl-transferase-mediated dUTP nick end labeling; H\&E, hematoxylin and eosin; HCC, hepatocellular carcinoma.

was used. HCC tissue with a total score $\geq 4$ was classified as having high expression and that with $<4$ was classified as having low expression. For P-STAT3, nuclear staining was considered to be a positive reaction. The P-STAT3 staining was classified as positive or negative $(\geq 10 \%$ or $<10 \%$ cells with nuclear staining, respectively). These expressions were evaluated manually under a light microscope (x100 magnification; Olympus Corporation). The Ki-67 index was calculated as the percentage of cells with positive nuclear Ki-67 immunostaining using e-Count cell counting software version 4.7 (e-Path Co, Ltd., Kanagawa, Japan) in those areas showing the highest nuclear labeling (so-called 'hot spots'), which were determined using a light microscope (x400 magnification). The median number of tumor cells counted was 322 (range, 165-583 cells) per sample.

Immunofluorescence staining. Cells were fixed in $4 \%$ paraformaldehyde for $20 \mathrm{~min}$ at room temperature. Following washing in PBS, the fixed cells were incubated in $50 \mathrm{mM}$ glycine for $20 \mathrm{~min}$ at room temperature, and washed again. The cells were then permeabilized in $0.1 \%$ Triton X-100 for $30 \mathrm{~min}$ at room temperature. The cells were washed in PBS and blocking was performed using 10\% goat serum (Wako Pure Chemical Industries, Ltd.) for $60 \mathrm{~min}$ at room temperature. The fixed cells were consecutively incubated with anti-PDIA3 mouse antibody (1:50) and anti-STAT3 rabbit antibody (cat. no. 12640S; 1:50; Cell Signaling Technology, Inc.), followed by
Alexa 488-labeled anti-rabbit IgG antibody (cat. no. A11031) and Alexa 568-labeled anti-mouse IgG antibody (cat. no. A11034) (both 1:1,000; Thermo Fisher Scientific, Inc.). The slides were mounted in medium containing DAPI, and the images were captured using a Digital Eclipse C1 TE2000-E confocal microscope (x1,000 magnification; Nikon Corporation, Tokyo, Japan)

Terminal deoxynucleotidyl-transferase-mediated dUTP nick end labeling (TUNEL) assay. HCC tissues fixed as described above ( $4 \mu \mathrm{m}$ thickness) were used for the TUNEL assay. The apoptotic cell death of HCC cells was determined by a TUNEL assay using an Apoptag ${ }^{\circledR}$ Peroxidase In Situ Apoptosis Detection kit (Merck KGaA). The peroxidase activity was visualized by 3,3' diaminobenzidine. The sections were then counterstained with hematoxylin at room temperature for 1 min and dehydrated. 99\% xylene with Malinol (Muto Pure Chemicals Co., Ltd.) was used as a water-insoluble mounting medium. Nuclear staining was considered a positive reaction. The images were captured under a light microscope (x400 magnification; Olympus). The TUNEL index was calculated by the same method as that used for the Ki-67 index. The median number of counted tumor cells was 337 (range, 179-649 cells) per sample.

Statistical analysis. The data are expressed as the mean \pm standard error of the mean or standard deviation 
A
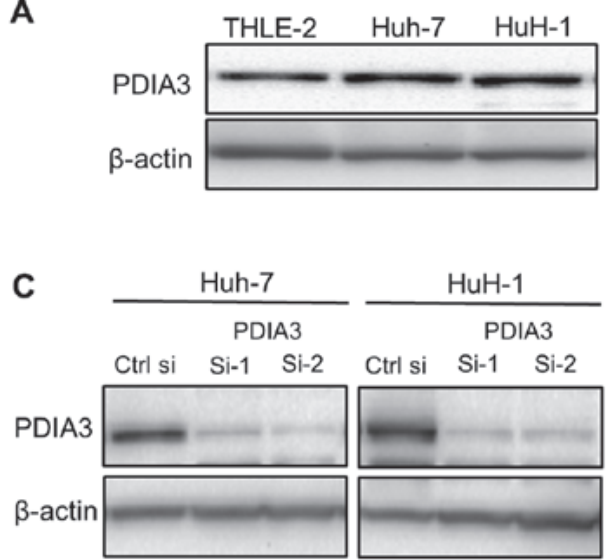

B

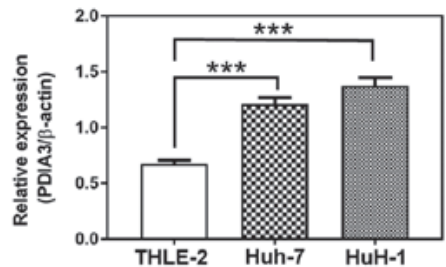

D

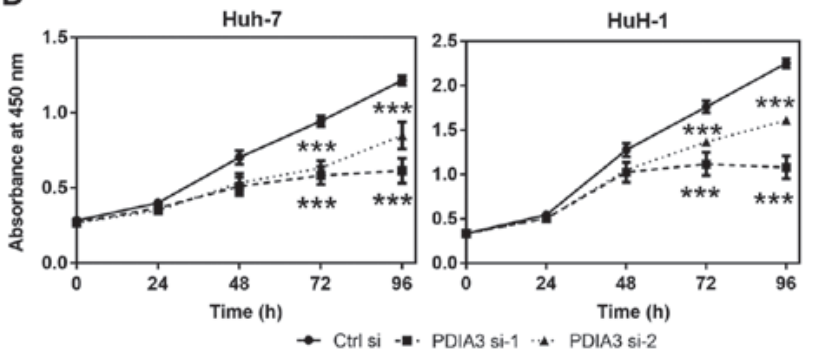

$\mathbf{F}$
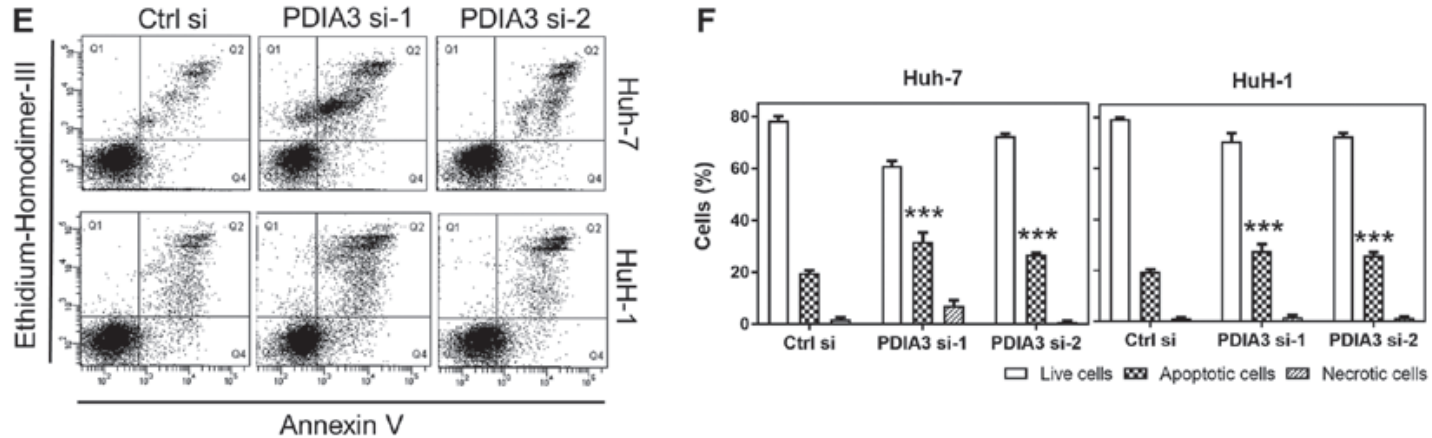

H
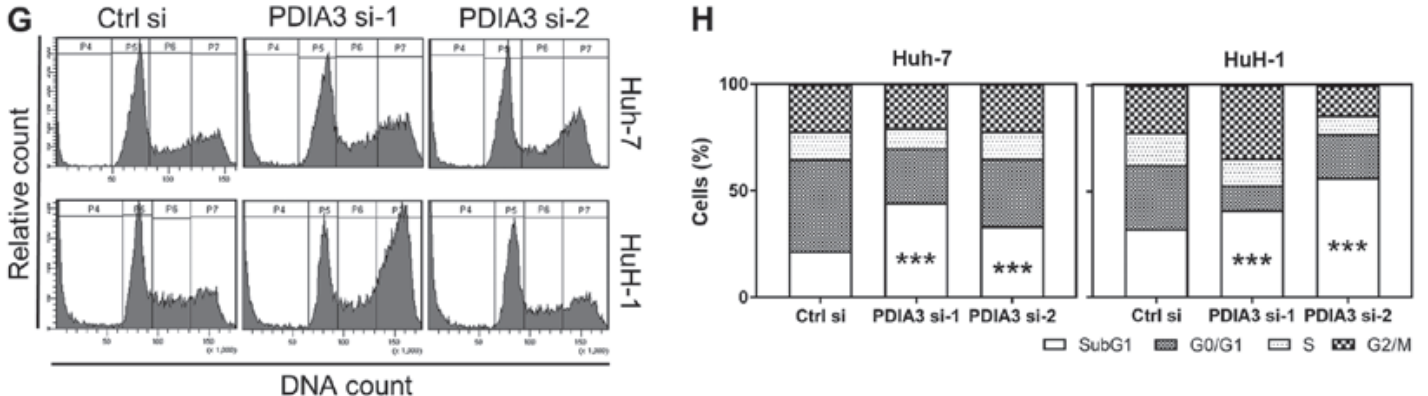

Figure 2. Effects of PDIA3 knockdown on cell proliferation, apoptosis and cell cycle in HCC cell lines. (A) Representative western blots of PDIA3 protein expression in normal hepatocyte THLE-2 and HCC Huh-7 and HuH-1 cells. (B) Relative quantification of the PDIA3 protein expression. The data are expressed as the mean \pm SEM. ${ }^{* * *}$ P $<0.001$ vs. THLE-2 (one-way ANOVA). (C) Representative western blots of the expression of PDIA3 in Huh-7 and HuH-1 cells lines transfected Ctrl si, PDIA3 si-1 and PDIA3 si-2. (D) Cell proliferation of the HCC cells transfected with Ctrl si, PDIA3 si-1 and PDIA3 si-2 was evaluated using the WST-8 cell counting reagent. At the indicated time points, the number of cells per well was estimated by measuring the absorbance (450 nm). The data are expressed as the mean $\pm \mathrm{SEM} .{ }^{* * * *} \mathrm{P}<0.001 \mathrm{vs}$. Ctrl si at each time point (two-way ANOVA). (E) Representative plots of the flow cytometry analysis of apoptosis. The apoptotic cells were counted by flow cytometry following double staining with annexin V and ethidium homodimer III. Q1 represents the necrotic cells; Q2 the late apoptotic cells; Q3 the live cells; and Q4 the early apoptotic cells. (F) The percentage of live, apoptotic and necrotic cells in the groups transfected with siRNAs. The data are expressed as the mean \pm SEM. ${ }^{* * *} \mathrm{P}<0.001 \mathrm{vs}$. Ctrl si (two-way ANOVA). (G) Representative histograms of flow cytometry analysis of the cell cycle, following propidium iodide staining. P4 represents the SubG1 (fragmented DNA); P5 the $\mathrm{G}_{0} / \mathrm{G}_{1}$ phase; P6 the S phase; and P7 the $\mathrm{G}_{2} / \mathrm{M}$ phase. $(\mathrm{H})$ The percentage of cells in each cell cycle phase following siRNA treatment. ${ }^{* * *} \mathrm{P}<0.001$ vs. Ctrl si (two-way ANOVA). These results were from $\geq 3$ independent experiments. PDIA3, protein disulfide-isomerase A3; HCC, hepatocellular carcinoma; PDIA si-1/PDIA si-2, PDIA3 siRNA; Ctrl si, control siRNA; ANOVA, analysis of variance; SEM, standard error of the mean.

(SD). Statistical comparisons between and among the groups were conducted using one-way analysis of variance (ANOVA) with Dunnett's post-hoc test, two-way ANOVA with Tukey's post-hoc test or a Mann-Whitney U-test. The clinicopathological parameters were analyzed using the $\chi^{2}$ and Fisher's exact tests. $\mathrm{P}<0.05$ was considered to indicate a statistically significant difference. All statistical analyses were performed using GraphPad Prism version 7.0 (GraphPad Software, Inc., La Jolla, CA, USA).

\section{Results}

PDIA3 expression is associated with cell proliferation and apoptosis in HCC tissues. To evaluate the effects of PDIA3 expression in HCC, cell proliferation, apoptosis and clinicopathological features were investigated in 53 HCC samples. The cell proliferation was evaluated using Ki-67 immunostaining, and apoptosis was measured by a TUNEL assay. The HCC tissues with high PDIA3 expression exhibited a 


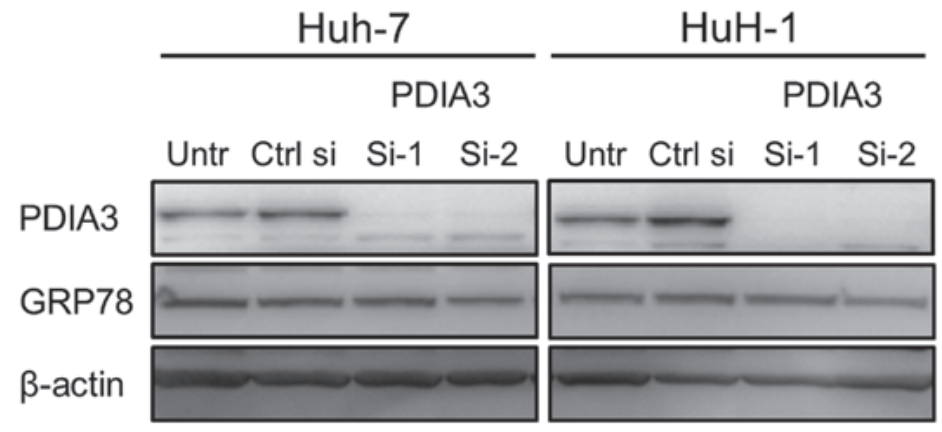

Figure 3. Endoplasmic reticulum stress levels in HCC cells with knockdown of PDIA3 expression. Huh-7 and HuH-1 cells were transfected with Ctrl si, PDIA3 si- 1 and PDIA 3 si-2 for $96 \mathrm{~h}$. Total protein was extracted for immunoblotting with antibodies against PDIA3, GRP78 and $\beta$-actin. The images are representative western blots demonstrating GRP78 protein expression following downregulation of PDIA3 expression in HCC cells. PDIA3, protein disulfide-isomerase A3; HCC, hepatocellular carcinoma; Untr, untreated control; PDIA si-1/PDIA si-2, PDIA3 siRNA; Ctrl si, control siRNA; GRP78, 78 kDa glucose-regulated protein.

significantly higher Ki-67 index than those with low expression (25.8 vs. 10.1\%, respectively; $\mathrm{P}<0.001$; Fig. $1 \mathrm{~A}$ and $\mathrm{B}$ ). By contrast, HCC tissues in which PDIA3 was highly expressed revealed significantly fewer apoptotic cells than those with low expression (2.4 vs. $8.9 \%$, respectively; $\mathrm{P}<0.001$; Fig. $1 \mathrm{~A}$ and $\mathrm{C}$ ). However, no associations were observed between the PDIA3 expression level and any clinicopathological features (Table I). These results indicate that $\mathrm{HCC}$ tissues with high PDIA3 expression are associated with increased cell proliferation and decreased apoptosis.

PDIA3 expression in HCC cells is higher than that in normal hepatocyte cells. The PDIA3 protein expression in HCC Huh-7 and HuH-1 cells was tested, and was demonstrated to be 1.7 and 2.0 times higher, respectively, than that in normal hepatocyte THLE- 2 cells $(\mathrm{P}<0.001$; Fig. $2 \mathrm{~A}$ and $\mathrm{B})$. This result indicates that Huh-7 and $\mathrm{HuH}-1$ are appropriate cell lines for a model of HCC with increased PDIA3 levels.

PDIA3 knockdown inhibits cell proliferation of HCC cells. To investigate the role of PDIA3 in the progression of $\mathrm{HCC}$, the proliferation of HCC cells was tested following PDIA3 knockdown. First, it was ascertained that PDIA3 si-1 and si-2 successfully suppressed PDIA3 expression in Huh-7 and HuH-1 cells (Fig. 2C). The proliferative ability of Huh-7 cells treated with PDIA3 si-1 and si-2 was 50.6 and $70.0 \%$ compared with those treated with Ctrl si at $96 \mathrm{~h}$, respectively. The proliferation of HuH-1 cells treated with PDIA3 si-1 and si-2 was 48.0 and $71.4 \%$ compared with the control group at 96 h, respectively ( $\mathrm{P}<0.001$ at 72 and 96 h; Fig. 2D). Overall, the PDIA3 knockdown significantly inhibited cell proliferation in the two HCC cell lines.

PDIA3 knockdown induces apoptosis in HCC cells. To investigate the effect of PDIA3 silencing on HCC cell proliferation, the apoptosis and cell cycle progression of HCC cells were investigated following PDIA3 knockdown. The silencing of PDIA3 induced apoptosis in the HCC cells $(\mathrm{P}<0.001$ compared with Ctrl si; Fig. 2E and F). Furthermore, the cell cycle analysis demonstrated that knockdown of PDIA3 significantly increased the SubG1 population and decreased the $G_{0} / G_{1}$ phase cells in the two HCC cell types $(\mathrm{P}<0.001$ compared with $\mathrm{Ctrl}$ si in the SubG1 population;
Fig. 2G and H). The increased SubG1 population signified the induction of apoptosis. These findings suggest that PDIA3 knockdown inhibits cell proliferation in HCC cell lines, likely through an apoptosis-dependent mechanism.

PDIA3 knockdown does not induce ER stress in HCC cells. As excessive ER stress causes apoptosis, the effect of the downregulation of PDIA3 expression on ER stress was investigated in the HCC cells. To evaluate the level of ER stress, the expression of ER stress marker GRP78 was tested following PDIA3 knockdown. No changes in GRP78 levels were observed, indicating that silencing of PDIA3 does not induce ER stress (Fig. 3).

PDIA3 interacts with STAT3 and regulates its phosphorylation in HCC cells. The interaction of PDIA3 with STAT3 in HCC cells was investigated. Double immunofluorescence staining revealed the colocalization (merge; yellow) of PDIA3 (red) and STAT3 (green) (Fig. 4A). PDIA3, an ER protein, was mainly observed in the cytoplasm where it colocalized with STAT3 (Fig. 4A; top panel; merged). Notably, PDIA3 also localized to the nucleus in $\sim 5 \%$ of Huh-7 cells (Fig. 4A; bottom panel). In these cells, nuclear PDIA3 tended to colocalize with STAT3 (Fig. 4A; bottom panel; merged). Additionally, the co-immunoprecipitation experiments demonstrated that PDIA3 was bound to STAT3 in the HCC cells (Fig. 4B). These results suggest a physiological interaction between PDIA3 and STAT3 in HCC cells. Furthermore, the western blotting revealed that inhibition of PDIA3 expression reduced P-STAT3 levels (Fig. 4C). This result indicates that PDIA3 is associated with STAT3 activation via a certain interaction in HCC cells.

Downstream targets of STAT3 are suppressed by PDIA3 knockdown in HCC cells. The expression of downstream targets of STAT3 was investigated by immunoblotting in HCC cells following treatment with PDIA3 siRNAs (Fig. 5A and B). The knockdown of PDIA3 led to a decrease in the expression of XIAP and Bcl-XL in Huh-7 cells, and that of survivin, Mcl-1, XIAP and cyclin D1 in HuH-1 cells. The difference between the expression of Mcl-1 and cyclin D1 in the Huh-7 cells for si-1 and si-2 is possibly due to off-target effects of the siRNAs. These results indicate that PDIA3 knockdown affects 

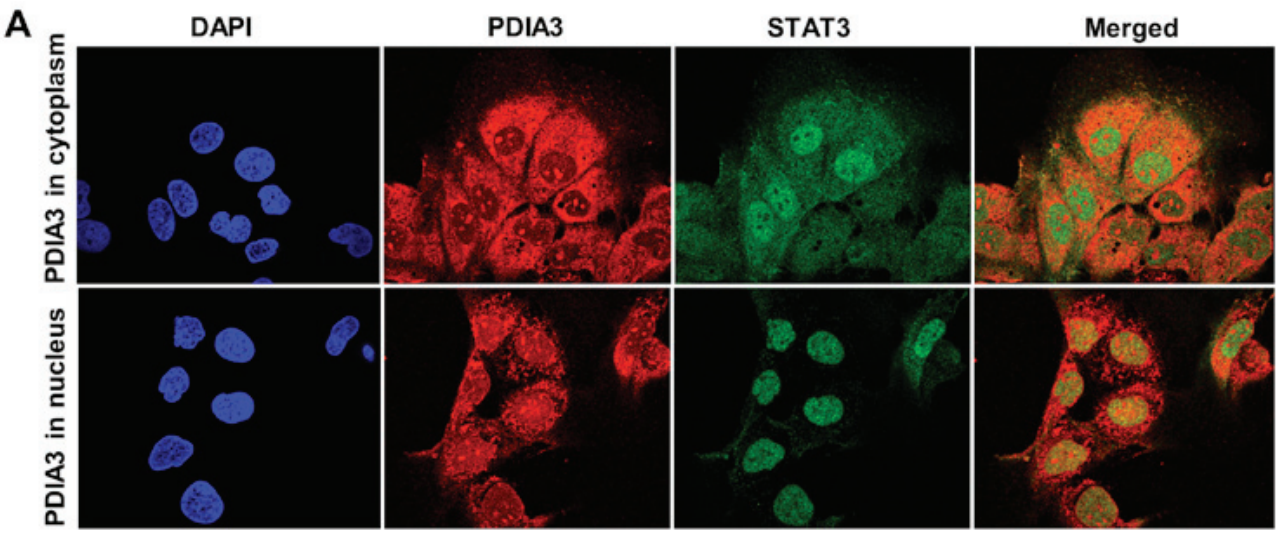

B
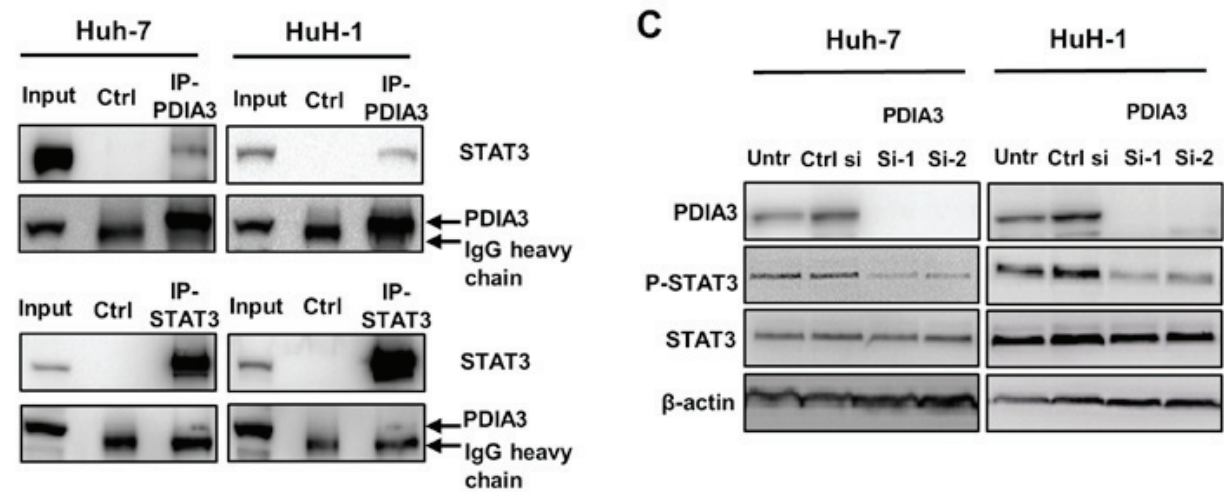

Figure 4. Association of PDIA3 and STAT3 in hepatocellular carcinoma cells. (A) Immunofluorescence staining for PDIA3 (red), STAT3 (green) and the nucleus (DAPI; blue) in Huh-7 cells (x1,000 magnification). The yellow color in the merged image indicates the colocalization of PDIA3 and STAT3. (B) A co-immunoprecipitation assay was performed using anti-PDIA3 or anti-STAT3 antibodies, and immunoblotting with anti-STAT3 or anti-PDIA3 antibodies, respectively. Normal mouse IgG was used for the Ctrl. (C) Huh-7 and HuH-1 cells were transfected with Ctrl si, PDIA3 si-1 and PDIA3 si-2 for 96 h. Total proteins were extracted and subjected to immunoblotting with antibodies against PDIA3, STAT3, P-STAT3 (Tyr705) and $\beta$-actin. Input represents the total cell lysate. PDIA3, protein disulfide-isomerase A3; STAT3, signal transducer and activator of transcription 3; P-STAT3, phosphorylated STAT3; Untr, untreated control; PDIA si-1/PDIA si-2, PDIA3 siRNA; Ctrl si, control siRNA; Ctrl, control.

apoptotic pathways by decreasing the levels of the downstream anti-apoptotic proteins of the STAT3 pathway in HCC cells.

PDIA3 knockdown with si-1 leads to a significant, but small, additional inhibitory effect on cell proliferation in HCC cells treated with AG490. The JAK/STAT3 signaling inhibitor AG490 suppressed the levels of P-STAT3 (Fig. 6A). Subsequently, to confirm that PDIA3 knockdown led to a decrease in cell proliferation mainly through STAT3 signaling, the cell proliferation of HCC cells treated with PDIA3 siRNAs was examined in the presence of AG490. AG490 markedly decreased cell proliferation in the two HCC cells $(\mathrm{P}<0.001$ at 72 and 96 h; Ctrl si vs. Ctrl si + AG490; Fig. 6B). In the Huh-7 cells, PDIA3 si-1 or si-2 + AG490 decreased the cell proliferation only by a further 7.2 or $5.2 \%$, respectively, compared with the effect of AG490 alone at 96 h, and only the additional effect of si-1 was statistically significant (PDIA3 si-1 + AG490 vs. Ctrl si + AG490, P<0.05; PDIA3 si-2 + AG490 vs. Ctrl si $+\mathrm{AG} 490, \mathrm{P}=0.22$; Fig. 6B). In the $\mathrm{HuH}-1$ cells, PDIA3 si-1 or si-2 + AG490 decreased the cell proliferation by 8.3 and $4.3 \%$ more than AG490 alone at $96 \mathrm{~h}$, respectively, and only the effect of si-1 was statistically significant $(\mathrm{P}<0.001$ PDIA3 si-1 + AG490 vs. Ctrl si + AG490, P<0.001; PDIA3 si-2 + AG490 vs. Ctrl si + AG490, P=0.086; Fig. 6B). Notably, these additional inhibitory effects of PDIA3 knockdown under AG490 treatment conditions were small compared with the inhibitory effect of AG490 alone (56.5 and 48.4\% decrease in Huh-7 and HuH-1, respectively, compared with Ctrl si at $96 \mathrm{~h}$ ). These results demonstrated that the inhibitory effect of PDIA3 knockdown on the proliferation of HCC cells with deactivated STAT3 was weak, suggesting that PDIA3 knockdown inhibits cell proliferation predominantly through STAT3 signaling.

PDIA3 expression is associated with P-STAT3 levels in HCC tissues. Immunohistochemical staining of $35 \mathrm{HCC}$ tissues revealed an association between PDIA3 and P-STAT3 levels. The HCC tissues that were positive for P-STAT3 exhibited significantly higher PDIA3 expression than those that were negative for P-STAT3 (mean PDIA3 expression score \pm SD, $4.8 \pm 0.8$ and $2.9 \pm 1.5$, respectively; $\mathrm{P}<0.001$; Fig. $7 \mathrm{~A}$ and $\mathrm{B})$. The HCC tissues that were P-STAT3 positive also demonstrated a tendency towards a higher Ki-67 index than those that were negative, although this was not statistically significant (mean Ki-67 index, 24.0 and 16.9\%, respectively; $\mathrm{P}=0.069$; Fig. 7C). By contrast, the P-STAT3-positive tissues demonstrated significantly fewer apoptotic cells than those that were negative (2.9 and 7.9\% apoptotic cells, respectively; $\mathrm{P}<0.001$; Fig. 7D). However, no association was observed between the P-STAT3 status and the clinicopathological features (Table I). Overall, PDIA3 expression was associated with a P-STAT3-positive status, which in turn was associated with decreased apoptosis in $\mathrm{HCC}$ tissues. 

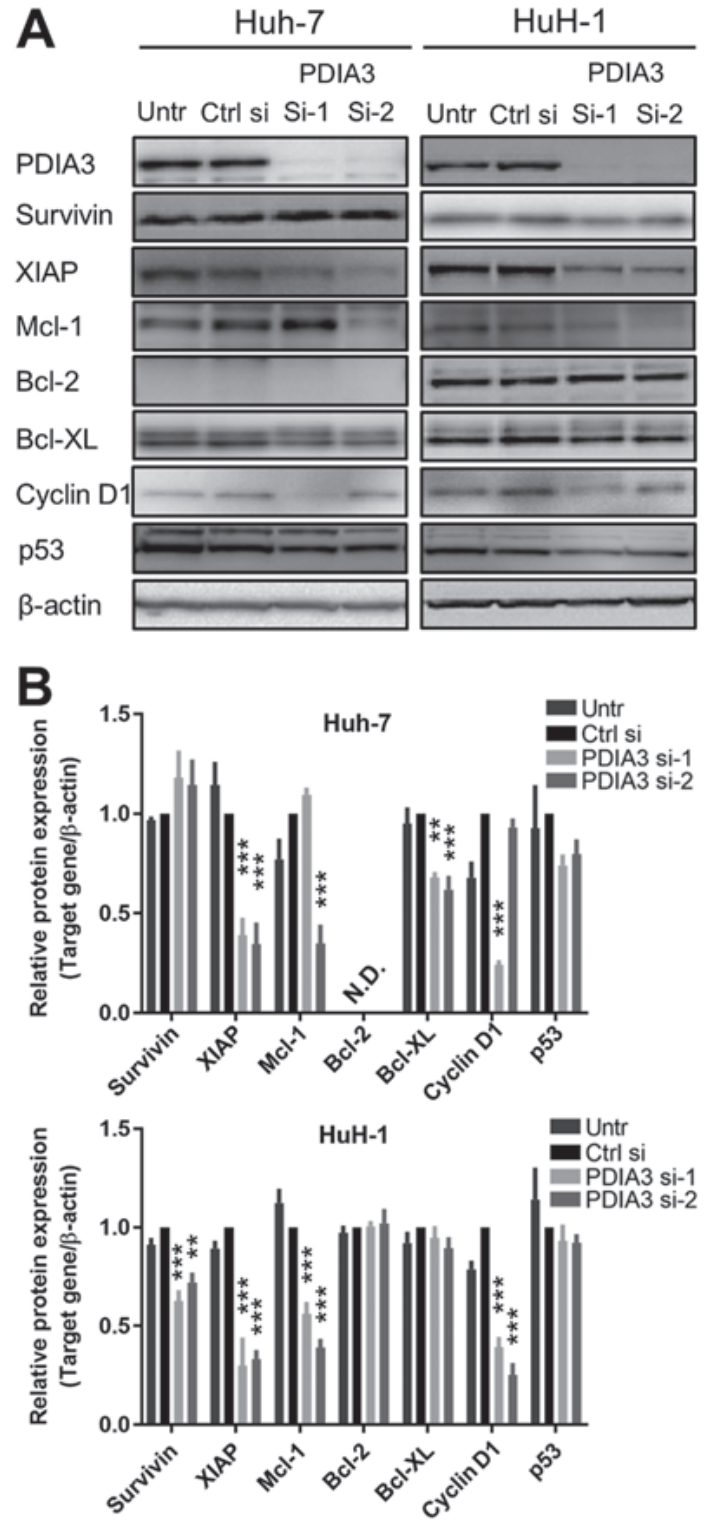

Figure 5. Downstream targets of signal transducer and activator of transcription 3 in hepatocellular carcinoma cells with silenced PDIA3. Huh-7 and $\mathrm{HuH}-1$ cells were transfected with Ctrl si, PDIA3 si-1 and PDIA3 si- 2 for $96 \mathrm{~h}$ (A) Total protein was extracted for immunoblotting with antibodies against PDIA3, survivin, XIAP, Mcl-1, Bcl-2, Bcl-XL, cyclin D1, p53 and $\beta$-actin (B) Relative quantification of the protein expression. The data are expressed as the mean \pm standard error of the mean. ${ }^{* *} \mathrm{P}<0.01,{ }^{* * *} \mathrm{P}<0.001$, vs. Ctrl si (two-way analysis of variance). PDIA3, protein disulfide-isomerase A3; XIAP, X-linked inhibitor of apoptosis protein; Mcl-1, induced myeloid leukemia cell differentiation protein Mcl-1; Bcl-2, B-cell lymphoma 2; Bcl-XL, Bcl-2-like protein 1; p53, cellular tumor antigen $\mathrm{p} 53$; Untr, untreated control; PDIA si-1/PDIA si-2, PDIA3 siRNA; Ctrl si, control siRNA, N.D., not detected.

\section{Discussion}

Mutations within several genes can lead to alterations in the expression of various essential proteins and change the biological behavior of cancer cells. Certain of these proteins may be used as prognostic markers. In previous studies of patients with HCC, the upregulation of PDIA3 expression was associated with poor prognosis $(20,23)$ and with increased cell proliferation and survival (20). To test the reproducibility of a previous study (20) on the collected
A

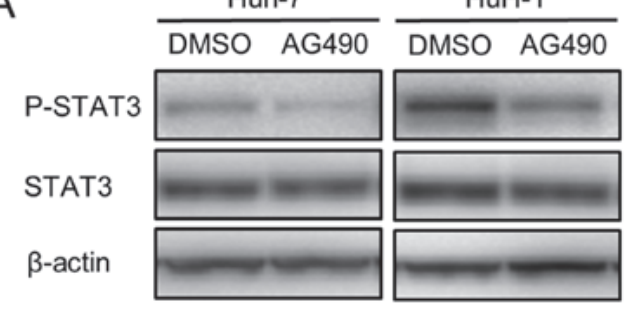

B $\rightarrow$ Ctrl si $\quad-$ - PDIA3 si-1 + AG490

Huh-7

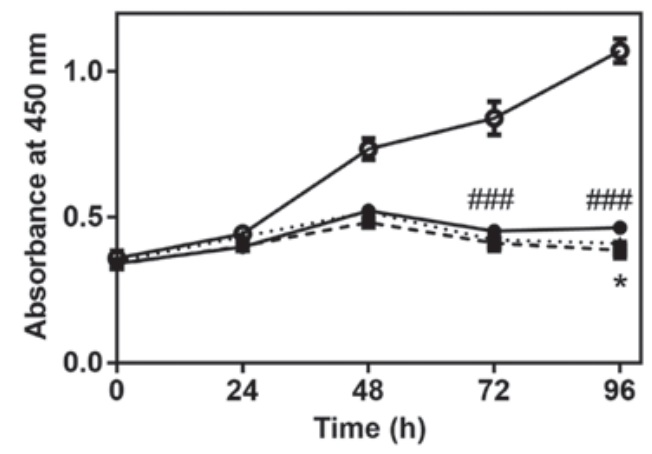

HuH-1

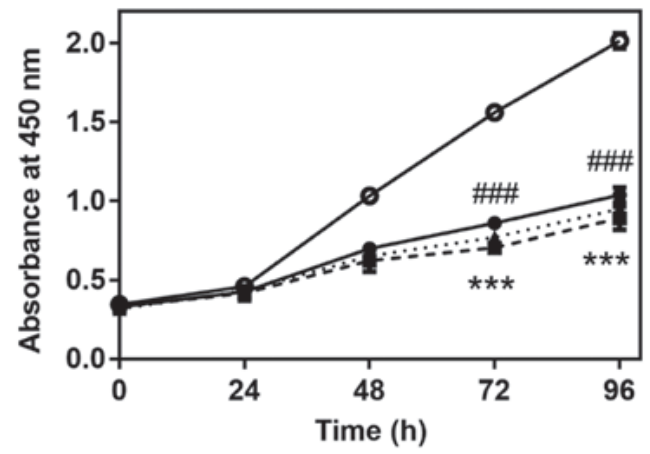

Figure 6. Effects of PDIA3 knockdown on HCC cell proliferation in the presence of AG490. (A) Representative western blots of P-STAT3 (Tyr705) levels following treatment with $100 \mu \mathrm{M}$ AG490 (a tyrosine-protein kinase JAK/STAT3 signaling inhibitor) or control (0.1\% DMSO) for $3 \mathrm{~h}$ in HCC Huh-7 and HuH-1 cells. Total protein was extracted and subjected to immunoblotting with antibodies against P-STAT3, STAT3 and $\beta$-actin. (B) Cell proliferation was evaluated using the WST- 8 cell counting reagent. Huh-7 and $\mathrm{HuH}-1$ cells were transfected with $\mathrm{Ctrl}$ si, PDIA3 si-1 and PDIA3 si-2, and treated with $25 \mu \mathrm{M}$ AG490. At the indicated time points, the number of cells per well was estimated by measuring the absorbance at $450 \mathrm{~nm}$. The data are expressed as the mean \pm standard error of the mean. ${ }^{\# \# \#} \mathrm{P}<0.001$ vs. Ctrl si; ${ }^{*} \mathrm{P}<0.05$, PDIA3 si- $1+$ AG490 vs. Ctrl si + AG490; ${ }^{* * * *} \mathrm{P}<0.001$, PDIA3 si-1 + AG490 vs. Ctrl si + AG490 (two-way analysis of variance). The results are from $\geq 3$ independent experiments. PDIA3, protein disulfide-isomerase A3; STAT3, signal transducer and activator of transcription 3; P-STAT3, phosphorylated STAT3; HCC, hepatocellular carcinoma; PDIA si-1/PDIA si-2, PDIA3 siRNA; Ctrl si, control siRNA.

samples in the present study and the contribution of PDIA3 to tumor progression, immunohistochemical staining of HCC tissues for PDIA3 was performed. PDIA3 expression in HCC was not associated with any clinicopathological features, including vascular invasion. However, high PDIA3 levels were associated with an increased $\mathrm{Ki}-67$ labeling index, and a lower TUNEL index, suggesting a contribution of PDIA3 to $\mathrm{HCC}$ cell proliferation and survival. Therefore, an in vitro evaluation of cell proliferation and apoptosis was conducted. 
A
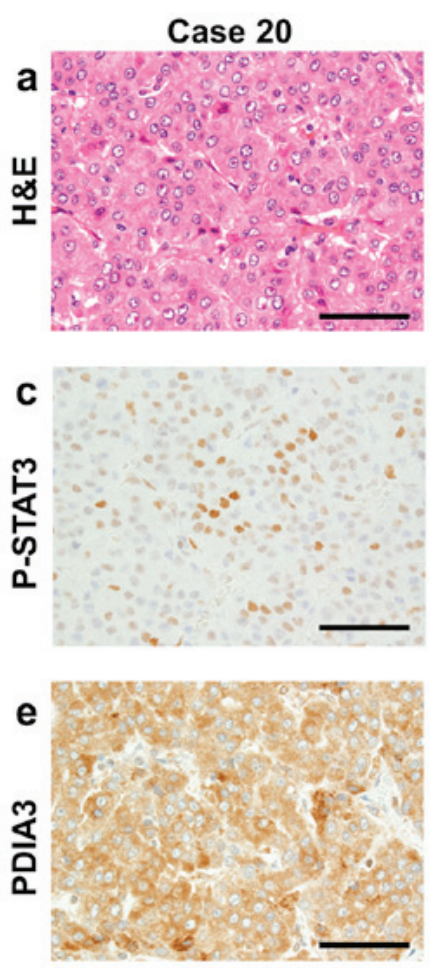
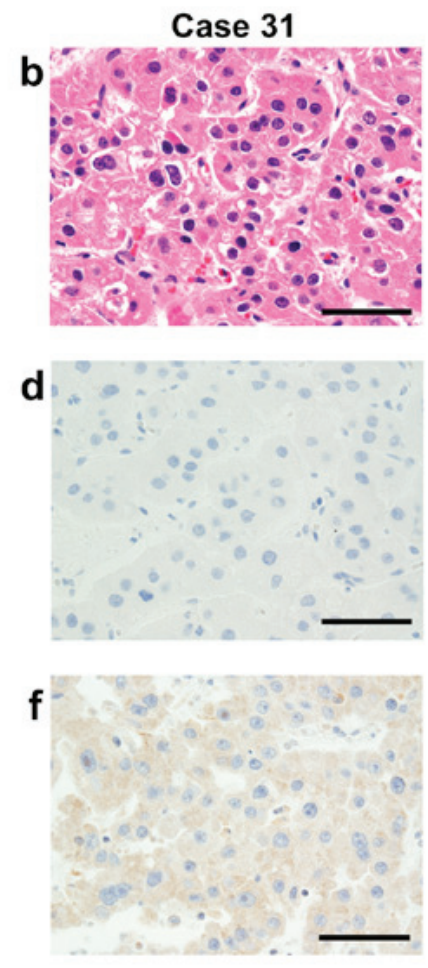
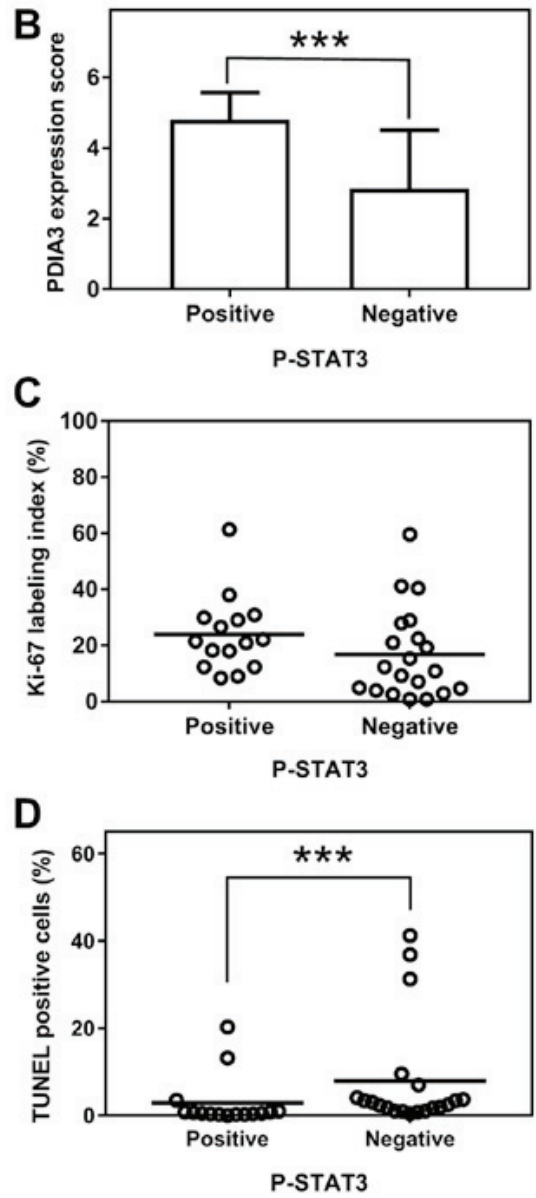

Figure 7. Association between P-STAT3 and PDIA3 expression, Ki-67 index and apoptotic cells in HCC tissues. (A) Representative histological and immunohistochemical staining of two HCC tissues (x600 magnification). The HCC tissues were examined by (a and b) H\&E staining, and immunohistochemistry staining with (c and d) anti-P-STAT3 (Tyr705) antibody and (e and f) anti-PDIA3 antibody. The HCC tissue of case 20 is P-STAT3 positive (a, c and e) and that of case 31 is P-STAT3 negative (b, $\mathrm{d}$ and $\mathrm{f}$ ). Scale bars, $50 \mu \mathrm{m}$. (B) The association between P-STAT3 status and PDIA3 expression in tissues from $35 \mathrm{HCC}$ cases. Values are expressed as the mean \pm standard deviation. ${ }^{* * *} \mathrm{P}<0.001$ (Mann-Whitney U-test). Scatter plots of percentages of (C) the Ki-67 index and (D) TUNEL-positive cells in HCC tissues positive ( $\geq 10 \%$ positive tumor cells) or negative $\left(<10 \%\right.$ positive tumor cells) for P-STAT3. ${ }^{* * *} \mathrm{P}<0.001$ (Mann-Whitney U-test). PDIA3, protein disulfide-isomerase A3; STAT3, signal transducer and activator of transcription 3; P-STAT3, phosphorylated STAT3; Ki-67, proliferation marker protein Ki-67; TUNEL, terminal deoxynucleotidyl-transferase-mediated dUTP nick end labeling; H\&E, hematoxylin and eosin; HCC, hepatocellular carcinoma.

Notably, the knockdown of PDIA3 significantly inhibited cell proliferation and induced apoptosis in HCC cells. These findings are reported for the first time in HCC. However, the question remains of how PDIA3 modulates cell proliferation and apoptosis in this cancer type.

ER chaperones protect cells from apoptosis induced by ER stress $(24,25)$. As PDIA3 is an ER chaperone, the possibility was considered that its knockdown may cause ER stress-dependent apoptosis. Therefore, the expression of an ER stress marker, GRP78 (26,27), was examined following suppression of PDIA3. However, the GRP78 levels did not increase, indicating that ER stress is not involved in the induction of apoptosis by PDIA3 knockdown in HCC cells.

PDIA3 is associated with several proteins and signaling pathways, including STAT3 (16-18), mammalian target of rapamycin complex $1(28,29)$, apurinic endonuclease/redox factor-1 (30), 1,25-dihydroxyvitamin D3 (31) and H2A histone family member X (32). Of these, STAT3 is particularly well known as an important pathway associated with cell proliferation and survival in HCC. In the present study, it was revealed that PDIA3 and STAT3 colocalized in the

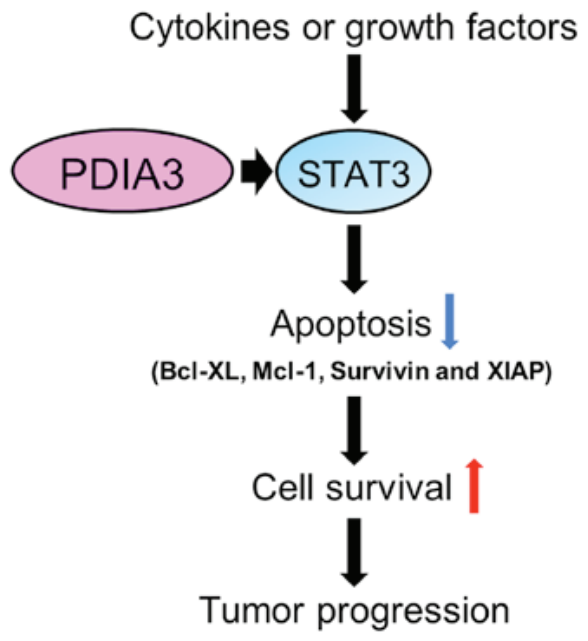

Figure 8. Flow diagram of the association of PDIA3 and the STAT3 signaling pathway in HCC. The STAT3 signaling pathway modulates cell survival in HCC. The progress of STAT3 signaling requires the expression of PDIA3. HCC, hepatocellular carcinoma; PDIA3, protein disulfide-isomerase A3; STAT3, signal transducer and activator of transcription 3; XIAP, X-linked inhibitor of apoptosis protein; Mcl-1, induced myeloid leukemia cell differentiation protein Mcl-1; Bcl-XL, Bcl-2-like protein 1. 
cytoplasm and nucleus of HCC cells and formed complexes. Furthermore, PDIA3 knockdown led to a decrease in the levels of P-STAT3. However, PDIA3 knockdown had little inhibitory effect on the cell proliferation in the presence of the JAK/STAT3 signaling inhibitor AG490. These findings may be the supportive evidence that PDIA3 functions mainly through the STAT3 signaling pathway. These results are consistent with those from several cancer cell lines $(18,19)$, suggesting that PDIA3 is involved in the phosphorylation process and the DNA-binding activity of STAT3. Furthermore, an association was observed between PDIA3 and P-STAT3 expression in HCC tissues. To the best of our knowledge, these data are the first to demonstrate the association between PDIA3 and P-STAT3 in human HCC specimens. To better understand the mechanism of STAT3 signaling-activation mediated by PDIA3, further assessments into the transportation into the nucleus, binding to DNA fragments and protection of STAT3 from dephosphorylation are required.

Furthermore, PDIA3 knockdown was revealed to lead to a decrease in the levels of certain proteins associated with the STAT3 signaling pathway. First, the cell cycle protein cyclin D1 decreased in HuH-1 but not in Huh-7 cells following PDIA3-si2 treatment. Additionally, the cell cycle analysis demonstrated no $\mathrm{G}_{0} / \mathrm{G}_{1}$ arrest. Within the cell cycle, the effect of PDIA3 silencing remains unclear. Next, PDIA3 knockdown was previously revealed to increase the expression of p53 and induce apoptosis in tumor cells in a p53-dependent manner $(19,29)$. However, in the present study, the expression of $\mathrm{p} 53$ was not increased following PDIA3 siRNA treatment in Huh-7 and HuH-1 cells, possibly because these cells have a homozygous loss-of-function mutation in p53 (33). Therefore, apoptosis was induced in Huh-7 and HuH-1 cells in a p53-independent manner. Finally, PDIA3 knockdown was revealed to decrease the levels of certain anti-apoptotic proteins, including survivin, XIAP, Mcl-1 and Bcl-XL. Therefore, it is hypothesized that PDIA3 expression in HCC promotes cell survival by modulating anti-apoptotic proteins (Fig. 8). Regarding the undetectable Bcl-2 expression in the Huh-7 cells, Wang et al (34) reported a similar result; however certain studies have detected it, but reported that it was lower in Huh-7 cells compared with other hepatoma cell lines $(35,36)$. There is a possibility that the expression of Bcl-2 was not detected in the present study due to different experimental conditions. Differences in the anti-apoptotic protein levels following PDIA3 knockdown were observed between the Huh-7 and HuH-1 cells. This may be due to crosstalk between STAT3 signaling and other transcriptional mechanisms (37).

The association between PDIA3 and STAT3 signaling in $\mathrm{HCC}$ was demonstrated in the present study. However, it remained unclear whether PDIA3 specifically associates with P-STAT3 as well as non-phosphorylated STAT3. PDIA3 colocalized with STAT3 in the cytoplasm and nucleus of the HCC cells. In addition, it was observed in the nucleus of HCC cells in which the majority of STAT3 detection occurred. Therefore, PDIA3 and P-STAT3 may interact in nucleus. The present findings indicated that PDIA3 mainly associates with P-STAT3, however, the immunofluorescence staining was not sufficient to support that. To the best of our knowledge, this issue remains unclear and further assessments are required to improve our understanding.
In HCC therapy, sorafenib inhibits not only the downstream signaling of the receptor for the vascular endothelial growth factor, but also the phosphorylation level of STAT3 (38-40). However, previous studies have documented that P-STAT3 is upregulated in sorafenib-resistant patients with HCC and sorafenib-resistant HCC cell lines that were established following long-term exposure to sorafenib $(41,42)$. In addition, dovitinib, a multi-targeted receptor tyrosine kinase inhibitor, is effective in sorafenib-resistant HCC cell lines due to inhibiting the STAT3 signaling pathway by a different mechanism (42). STAT3 serves an important role in sorafenib resistance and would therefore be an important therapeutic target. In addition, PDIA3 is known to contribute to chemoresistance (43) and radio-resistance (19) and, since it modulates the P-STAT3 levels, it is a potential therapeutic target in sorafenib-resistant $\mathrm{HCC}$. The association of PDIA3 with chemoresistance in HCC requires further elucidation.

In conclusion, PDIA3 is upregulated in HCC tissues and cell lines, and is associated with cell survival factors. In the present study, it was revealed that the poor prognosis in HCC associated with a high expression of PDIA3 may be induced by a complex formation between PDIA3 and STAT3 in HCC cells, regulating the transcriptional potential of STAT3. These findings suggest that PDIA3 participates in the aggressive phenotype of HCC through its association with STAT3 signaling, hence PDIA3 is considered a potential therapeutic target for the treatment of HCC.

\section{Acknowledgements}

The authors thank Dr Eiji Uchida, Dr Hidemi Takahashi, Ms. Masumi Shimizu, Ms. Kiyoko Kawahara, Mr. Takenori Fuji, Mr. Kiyoshi Teduka, Ms. Yoko Kawamoto and Ms. Taeko Kitamura, Nippon Medical School, Tokyo, Japan, for their assistance.

\section{Funding}

This study was supported by Grants-in-aid for the Clinical Rebiopsy Bank Project for Comprehensive Cancer Therapy Development from the Ministry of Education, Culture, Sports, Science and Technology, Japan (grant no. S1311022).

\section{Availability of data and materials}

The datasets used and/or analyzed during the current study are available from the corresponding author on reasonable request.

\section{Authors' contributions}

RK, ZN and KI were involved in the conception and design of the study; RK, KI, YK, SK, WXP, MK, HT and NT performed the experiments; RK, KI, RW and HY analyzed the data; RK drafted the manuscript; $\mathrm{HY}$ and $\mathrm{ZN}$ reviewed and edited the manuscript. All authors have read and approved the final manuscript.

\section{Ethics approval and consent to participate}

This study was conducted according to the Declaration of Helsinki and the Japanese Society of Pathology, and was given 
official approval by the Ethics Committee of Nippon Medical School Hospital, Tokyo, Japan (approval no. 29-03-908). Written informed consent was obtained from all patients.

\section{Patient consent for publication}

Written informed consent was obtained from the patients.

\section{Competing interests}

The authors declare that they have no competing interests.

\section{References}

1. Torre LA, Bray F, Siegel RL, Ferlay J, Lortet-Tieulent J and Jemal A: Global cancer statistics, 2012. CA Cancer J Clin 65: 87-108, 2015

2. Fitzmorris P, Shoreibah M, Anand BS and Singal AK: Management of hepatocellular carcinoma. J Cancer Res Clin Oncol 141: 861-876, 2015.

3. Imamura H, Matsuyama Y, Tanaka E, Ohkubo T, Hasegawa K, Miyagawa S, Sugawara Y, Minagawa M, Takayama T, Kawasaki S, et al: Risk factors contributing to early and late phase intrahepatic recurrence of hepatocellular carcinoma after hepatectomy. J Hepatol 38: 200-207, 2003.

4. Bellavance EC, Lumpkins KM, Mentha G, Marques HP, Capussotti L, Pulitano C, Majno P, Mira P, Rubbia-Brandt L, Ferrero A, et al: Surgical management of early-stage hepatocellular carcinoma: Resection or transplantation? J Gastrointest Surg 12: 1699-1708, 2008.

5. Nakajima Y, Ko S, Kanamura T, Nagao M, Kanehiro H, Hisanaga M, Aomatsu Y, Ikeda N and Nakano H: Repeat liver resection for hepatocellular carcinoma. J Am Coll Surg 192: 339-344, 2001.

6. Ge S and Huang D: Systemic therapies for hepatocellular carcinoma. Drug Discov Ther 9: 352-362, 2015.

7. Daher S, Massarwa M, Benson AA and Khoury T: Current and Future Treatment of Hepatocellular Carcinoma: An Updated Comprehensive Review. J Clin Transl Hepatol 6: 69-78, 2018.

8. Swamy SG, Kameshwar VH, Shubha PB, Looi CY, Shanmugam MK, Arfuso F, Dharmarajan A, Sethi G, Shivananju NS and Bishayee A: Targeting multiple oncogenic pathways for the treatment of hepatocellular carcinoma. Target Oncol 12: 1-10, 2017.

9. Yu H, Pardoll D and Jove R: STATs in cancer inflammation and immunity: A leading role for STAT3. Nat Rev Cancer 9: 798-809, 2009.

10. Nikolaou K, Sarris M and Talianidis I: Molecular pathways: The complex roles of inflammation pathways in the development and treatment of liver cancer. Clin Cancer Res 19: 2810-2816, 2013.

11. Subramaniam A, Shanmugam MK, Perumal E, Li F, Nachiyappan A, Dai X, Swamy SN, Ahn KS, Kumar, Tan BK, et al: Potential role of signal transducer and activator of transcription (STAT)3 signaling pathway in inflammation, survival, proliferation and invasion of hepatocellular carcinoma. Biochim Biophys Acta 1835: 46-60, 2013

12. Wu WY, Li J, Wu ZS, Zhang CL, Meng XL and Lobie PE: Prognostic significance of phosphorylated signal transducer and activator of transcription 3 and suppressor of cytokine signaling 3 expression in hepatocellular carcinoma. Exp Ther Med 2: 647-653, 2011.

13. Zhang CH, Xu GL, Jia WD, Li JS, Ma JL, Ren WH, Ge YS, Yu JH, Liu WB and Wang W: Activation of STAT3 signal pathway correlates with twist and E-cadherin expression in hepatocellular carcinoma and their clinical significance. J Surg Res 174: 120-129, 2012.

14. Mano Y, Aishima S, Fujita N, Tanaka Y, Kubo Y, Motomura T, Taketomi A, Shirabe K, Maehara Y and Oda Y: Tumor-associated macrophage promotes tumor progression via STAT3 signaling in hepatocellular carcinoma. Pathobiology 80: 146-154, 2013.

15. Hettinghouse A, Liu R and Liu CJ: Multifunctional molecule ERp57: From cancer to neurodegenerative diseases. Pharmacol Ther 181: 34-48, 2018.

16. Ndubuisi MI, Guo GG, Fried VA, Etlinger JD and Sehgal PB: Cellular physiology of STAT3: Where's the cytoplasmic monomer? J Biol Chem 274: 25499-25509, 1999.
17. Eufemi M, Coppari S, Altieri F, Grillo C, Ferraro A and Turano C: ERp57 is present in STAT3-DNA complexes. Biochem Biophys Res Commun 323: 1306-1312, 2004.

18. Chichiarelli S, Gaucci E, Ferraro A, Grillo C, Altieri F, Cocchiola R, Arcangeli V, Turano C and Eufemi M: Role of ERp57 in the signaling and transcriptional activity of STAT3 in a melanoma cell line. Arch Biochem Biophys 494: 178-183, 2010.

19. Choe MH, Min JW, Jeon HB, Cho DH, Oh JS, Lee HG, Hwang SG, An S, Han YH and Kim JS: ERp57 modulates STAT3 activity in radioresistant laryngeal cancer cells and serves as a prognostic marker for laryngeal cancer. Oncotarget 6: 2654-2666, 2015.

20. Takata H, Kudo M, Yamamoto T, Ueda J, Ishino K, Peng WX, Wada R, Taniai N, Yoshida H, Uchida E, et al: Increased expression of PDIA3 and its association with cancer cell proliferation and poor prognosis in hepatocellular carcinoma. Oncol Lett 12: 4896-4904, 2016.

21. Livak KJ and Schmittgen TD: Analysis of relative gene expression data using real-time quantitative PCR and the $2(-\Delta \Delta$ C(T)) method. Methods 25: 402-408, 2001.

22. Ishino K, Kudo M, Peng WX, Kure S, Kawahara K, Teduka K, Kawamoto Y, Kitamura T, Fujii T, Yamamoto T, et al: 2-Deoxy-d-glucose increases GFAT1 phosphorylation resulting in endoplasmic reticulum-related apoptosis via disruption of protein N-glycosylation in pancreatic cancer cells. Biochem Biophys Res Commun 501: 668-673, 2018.

23. Liu M, Du L, He Z, Yan L, Shi Y, Shang J and Tang H: Increased ERp57 Expression in HBV-Related Hepatocellular Carcinoma: Possible Correlation and Prognosis. Biomed Res Int 2017: 1252647, 2017.

24. Ni M and Lee AS: ER chaperones in mammalian development and human diseases. FEBS Lett 581: 3641-3651, 2007.

25. Corazzari M, Gagliardi M, Fimia GM and Piacentini M: Endoplasmic reticulum stress, unfolded protein response, and cancer cell fate. Front Oncol 7: 78, 2017.

26. Bánhegyi G, Baumeister P, Benedetti A, Dong D, Fu Y, Lee AS, Li J, Mao C, Margittai E, Ni M, et al: Endoplasmic reticulum stress. Ann N Y Acad Sci 1113: 58-71, 2007.

27. Luo B and Lee AS: The critical roles of endoplasmic reticulum chaperones and unfolded protein response in tumorigenesis and anticancer therapies. Oncogene 32: 805-818, 2013.

28. Ramírez-Rangel I, Bracho-Valdés I, Vázquez-Macías A, Carretero-Ortega J, Reyes-Cruz G and Vázquez-Prado J: Regulation of mTORC1 complex assembly and signaling by GRp58/ERp57. Mol Cell Biol 31: 1657-1671, 2011.

29. Hussmann M, Janke K, Kranz P, Neumann F, Mersch E, Baumann M, Goepelt K, Brockmeier U and Metzen E: Depletion of the thiol oxidoreductase ERp57 in tumor cells inhibits proliferation and increases sensitivity to ionizing radiation and chemotherapeutics. Oncotarget 6: 39247-39261, 2015.

30. Grillo C, D'Ambrosio C, Scaloni A, Maceroni M, Merluzzi S, Turano $\mathrm{C}$ and Altieri F: Cooperative activity of Ref-1/APE and ERp57 in reductive activation of transcription factors. Free Radic Biol Med 41: 1113-1123, 2006.

31. Sequeira VB, Rybchyn MS, Tongkao-On W, Gordon-Thomson C, Malloy PJ, Nemere I, Norman AW, Reeve VE, Halliday GM, Feldman D, et al: The role of the vitamin D receptor and ERp57 in photoprotection by $1 \alpha, 25$-dihydroxyvitamin D3. Mol Endocrinol 26: 574-582, 2012.

32. Krynetskaia NF, Phadke MS, Jadhav SH and Krynetskiy EY: Chromatin-associated proteins HMGB1/2 and PDIA3 trigger cellular response to chemotherapy-induced DNA damage. Mol Cancer Ther 8: 864-872, 2009.

33. Forbes SA, Beare D, Boutselakis H, Bamford S, Bindal N, Tate J, Cole CG, Ward S, Dawson E, Ponting L, et al: COSMIC: Somatic cancer genetics at high-resolution. Nucleic Acids Res 45 (D1): D777-D783, 2017.

34. Wang B, Ni Z, Dai X, Qin L, Li X, Xu L, Lian J and He F: The Bcl-2/xL inhibitor ABT-263 increases the stability of Mcl-1 mRNA and protein in hepatocellular carcinoma cells. Mol Cancer 13: 98, 2014.

35. Chen P, Hu T, Liang Y, Jiang Y, Pan Y, Li C, Zhang P, Wei D, Li P, Jeong LS, et al: Synergistic inhibition of autophagy and neddylation pathways as a novel therapeutic approach for targeting liver cancer. Oncotarget 6: 9002-9017, 2015.

36. Zhou M, Zhang Q, Zhao J, Liao M, Wen S and Yang M: Phosphorylation of Bcl-2 plays an important role in glycochenodeoxycholate-induced survival and chemoresistance in HCC. Oncol Rep 38: 1742-1750, 2017.

37. Zheng HC: The molecular mechanisms of chemoresistance in cancers. Oncotarget 8: 59950-59964, 2017. 
38. Tai WT, Cheng AL, Shiau CW, Huang HP, Huang JW, Chen PJ and Chen KF: Signal transducer and activator of transcription 3 is a major kinase-independent target of sorafenib in hepatocellular carcinoma. J Hepatol 55: 1041-1048, 2011.

39. Gu F-M, Li QL, Gao Q, Jiang JH, Huang XY, Pan JF, Fan J and Zhou J: Sorafenib inhibits growth and metastasis of hepatocellular carcinoma by blocking STAT3. World J Gastroenterol 17: 3922-3932, 2011.

40. Huang CY, Lin CS, Tai WT, Hsieh CY, Shiau CW, Cheng AL and Chen KF: Sorafenib enhances radiation-induced apoptosis in hepatocellular carcinoma by inhibiting STAT3. Int J Radiat Oncol Biol Phys 86: 456-462, 2013.

41. van Malenstein H, Dekervel J, Verslype C, Van Cutsem E, Windmolders P, Nevens F and van Pelt J: Long-term exposure to sorafenib of liver cancer cells induces resistance with epithelial-to-mesenchymal transition, increased invasion and risk of rebound growth. Cancer Lett 329: 74-83, 2013
42. Tai WT, Cheng AL, Shiau CW, Liu CY, Ko CH, Lin MW, Chen PJ and Chen KF: Dovitinib induces apoptosis and overcomes sorafenib resistance in hepatocellular carcinoma through SHP-1-mediated inhibition of STAT3. Mol Cancer Ther 11: 452-463, 2012.

43. Cicchillitti L, Della Corte A, Di Michele M, Donati MB, Rotilio D and Scambia G: Characterisation of a multimeric protein complex associated with ERp57 within the nucleus in paclitaxel-sensitive and -resistant epithelial ovarian cancer cells: The involvement of specific conformational states of $\beta$-actin. Int J Oncol 37: 445-454, 2010.

44. Brierley JD, Gospodarowicz MK and Wittekind C (eds): TNM Classification of Malignant Tumours, 8th edition. Wiley-Blackwell, New York, NY, 2016. 